SO I LEFT, NOW WHAT?

SOCIAL SERVICE WORKERS PERSPECTIVE ON IMMIGRANT WOMEN'S SERVICE UTILIZATION AFTER LEAVING AN ABUSIVE RELATIONSHIP.

By

Shirley Owusuaa Asiamah, BSW, University of Windsor, 2014

\author{
An MRP \\ Presented to Ryerson University \\ In partial fulfillment of the \\ requirements for the degree of \\ Master of Social Work \\ In the Program of \\ Social Work
}

Toronto, Ontario, Canada, 2016

() Shirley Owusuaa Asiamah 2016 


\section{AUTHOR'S DECLARATION FOR ELECTRONIC SUBMISSION OF A MRP}

I hereby declare that I am the sole author of this MRP. This is a true copy of the MRP, including any required final revisions.

I authorize Ryerson University to lend this MRP to other institutions or individuals for the purpose of scholarly research

I further authorize Ryerson University to reproduce this MRP by photocopying or by other means, in total or in part, at the request of other institutions or individuals for the purpose of scholarly research.

I understand that my MRP may be made electronically available to the public. 


\title{
ABSTRACT \\ SO I LEFT, NOW WHAT? \\ SOCIAL SERVICE WORKERS PERSPECTIVE ON IMMIGRANT WOMEN'S SERVICE UTILIZATION AFTER LEAVING AN ABUSIVE RELATIONSHIP.
}

\author{
Master of Social Work, 2016 \\ Shirley Owusuaa Asiamah \\ Program of Social Work, \\ Ryerson University
}

Through in-depth interviews, this study explores three service provider's views on immigrant women's experiences while they accessed and utilized services after leaving an abusive relationship. A phenomenological method of inquiry was used to examine services that are available to meet the needs of immigrant women, and the workers' views on women's experiences while seeking assistance. The study focuses on an intersecting analysis of the limitations on three levels: services that assist women, the systems of community resources that women utilize, and the broader structural issues such as funding that affect social service organizations. This study includes a discussion of the coordinated community approach as a recommendation for improved assistance for abused women.

Key Words: Immigrant women, Domestic violence, Intersectionality, Social service 


\section{ACKNOWLEDGEMENTS}

I am grateful that I have had this opportunity to conduct this research; it has been a learning experience for me. But I would not have being able to do all this without the help of my strong supportive network.

First of all, I would like to thank God. It is by His grace that I have been able to come this far. I would also want to thank my family for all the support that they have given me throughout this period. It's by your prayers and encouragement that has held me through all circumstances.

I would also like to thank my research supervisor, Susan Silver for the continuous advice, help and encouragement throughout this research process. Thank you for always taking time to listen to my questions and giving me suggestions on how to go about it. Your contribution went a long way in this process.

Special thanks to the three workers who were willing to participate in this study and provided their stories and experiences. I would not have been able to accomplish anything without your contribution.

I would like to thank all my classmates for all the motivation and conversations we shared. We finally made it; it's the end of the road, and I appreciate all of you for supporting me in one way or the other. I would also want to thank all my friends for always being there and encouraging me whenever I wanted to give up. You are well appreciated.

I would also like to give a special thanks to Sherrie for her support and guidance throughout this journey.

Finally, I would also like to extend my admiration and acknowledgement to all the agencies that work and support immigrant women who have been abused. 


\section{DEDICATION}

This research is dedicated to any woman who has experienced any form of abuse, especially immigrant families. As immigrants, it is our resilience and strengths that keeps us going in all adversities. 


\section{TABLE OF CONTENTS}

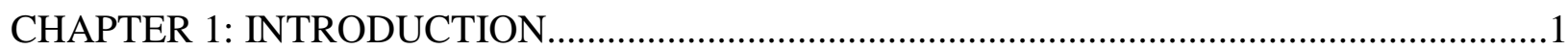

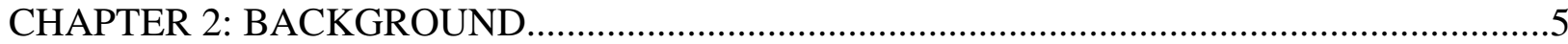

Immigration Policies on Abused Women

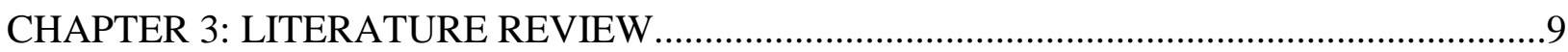

Resource Availability

Voices of Abused Women

Police and the Criminal Justice System (CJS)

Advocacy Services

CHAPTER 4: THEORETICAL FRAMEWORK...............................................................20

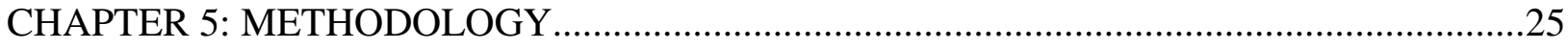

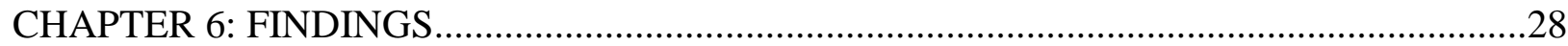

CHAPTER 7: IMPLICATION AND CONCLUSION....................................................46

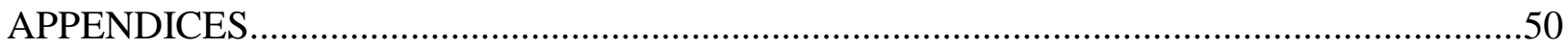

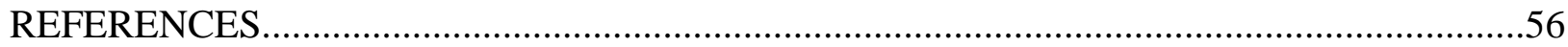




\section{LIST OF APPENDICES}

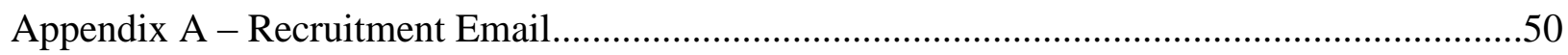

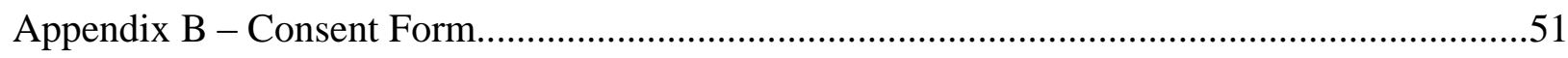

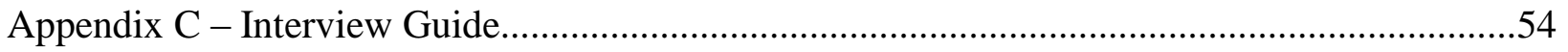




\section{CHAPTER 1: INTRODUCTION}

Intimate partner violence (IPV) is an important issue that affects millions of people regardless of age, gender, economic status, race, religion, ethnicity, sexual orientation, or educational background (WHO, 2012). IPV occurs when control is exerted by current or former partner on the other partner, which results in the experience or threat of physical, sexual violence, financial or psychological/emotional abuse (Hyman et al., 2006). Domestic violence (DV) is similar to intimate partner violence, however, DV can be experienced from partner, expartners or family members, whereas IPV is experienced from just a partner or an ex-partner (Campbell, 2009). According to Statistics Canada, "Intimate partner violence, including both spousal and dating violence, accounts for one in every four violent crimes reported to police" (Section 3: Intimate partner violence, 2013 para. 2). However, these are the numbers that get reported; there are still cases of abuse that go unreported (Hyman, Forte, Mont, Romans, \& Cohen, 2006). For the purpose of this research the terms DV and IPV will be used interchangeably to discuss the abuse immigrant women experience. IPV and DV are experienced by both males and females who are in homosexual or heterosexual relationships. Golding (1999) argues men are as likely as women to be victims of abuse; however the impact of the abuse is different for both genders. This research will focus on the violence experienced by immigrant women in heterosexual relationships but recognizes that DV or IPV can be experienced by anyone.

Research, policies, and programs on DV and IPV have focused on finding ways to eradicate the problem, however the issue still exists. This research study will focus on the service providers' perspective on the service utilization of immigrant women after they leave abusive relationships. This study seeks to examine the resources that are available to abused immigrant 
women, and explore the experiences of service providers as they assist women to seek community services. The study will also focus on analyzing the barriers and challenges that are present while women seek help and how these barriers play a role in women's decision to leave or stay in the abusive relationship.

This qualitative exploratory study utilizes phenomenology as a research methodology to explore service provider's perspectives on the experiences of immigrant women after they leave an abusive relationship. The theoretical frameworks of critical race feminism and intersectionality are used to understand and analyze women's experiences while accessing resources within social structures, and the intersecting identities that influence their experiences. This research also recognizes women's experiences in seeking resources as heterogeneous and as such it will focus on understanding their unique and shared experiences. To achieve the objectives of this the research, these questions guided the research process: 1). what happens after the women decide to leave an abusive relationship? 2). what resources or policies influence women's decision to stay or leave the abusive relationship? 3). what are some challenges service providers experience whiles trying to meet the needs of immigrant women? 4). How can we improve the experiences of immigrant women?

In this research study, the term immigrant women will refer to as women who were born outside their current host country, but have migrated due to various reasons. This group includes newcomers, refugees, temporary residents and those without any form of immigration status. Immigrants face diverse oppression, however, women's violence is the most common form of victimization immigrant women face (Briones-Vozmediano, La Parra, \& Vives-Cases, 2014; Guruge \& Humphreys, 2009; Hyman, Mason, Helene, Manuel, \& Kanagaratnam, 2006). Immigrant women experience social inequality in society due to their intersecting identities of 
gender, social class, nationality and ethnicity in society. An immigrant woman's response to abuse is influenced by her intersecting identities, her social location and resource availability. An immigrant woman's response to abuse is dependent on factors such as language, cultural factors, resources available, immigration status and level of acculturation into the host country. The experiences of abused immigrant women are not the same, since the group is not homogeneous (Hyman et al., 2006). However, there are some similarities and shared experiences due to the common experiences of migration, such as the challenge of dealing with abuse in addition to acculturation into the new country.

This research is essential because there has been lots of research examining why women do not leave abusive relationships, and not enough on what happens to them after they leave (Meyer, 2012; Rhodes \& Mckenzie, 1998). Research and advocacy groups have also focused on educating communities on the importance of leaving an abusive relationship, but not about what to do once they have left. In a study by Sullivan, Basta, Tan, \& Davidson (1992) the "needs assessment found that the majority of the project participants felt they lacked the very resources hypothesized to increase their chances of escaping their assailants" (p. 274). This shows the gap in women's needs and as such, this research will analyze the links between needs of immigrant women, their help seeking behaviour and their responses to the violence. This area of domestic violence for immigrant women has been undocumented and unexamined until recently (Vidales, 2010). However, there remains a gap in the research on immigrant women experiences after they leave an abusive relationship. As such, this research aims at creating knowledge by filling this gap. This research study will additionally provide knowledge in the application of intersectionality to anti-violence social work. 


\section{CHAPTER 1.1: SOCIAL LOCATION}

In understanding our power, privilege and biases in the research we conduct, positionality is vital, as it analyzes the dynamics between ourselves and our research (Madison, 2004). In reflecting on my social location, I position myself as a woman, heterosexual, African, and an immigrant. These positions are reflective of my life experiences and these experiences have informed this research. Louis \& Barton (2002) argues our subjectivity, positionality and life history influence the type of research we do and the people we hope to work with in the research.

My interest in understanding the experiences of immigrant women after they leave abusive relationships stems from my own experience accessing settlement services when I migrated to Canada six years ago. I faced diverse challenges in accessing these resources because of factors like the unawareness of the availability of such resources, and some of the resources I found were focused for the mainstream population were not suitable for my needs. My immigrant identities impacted my experience as I was seeking formal resources in the community. The barriers I experienced within these agencies, due to their policies, resulted in my experience of structural oppression. The challenges I encountered shaped this research as I was interested in the experiences of other immigrants. I came into this research as an outsider because I do not have prior experiences of domestic abuse; however, I do have an interest in understanding how violence among immigrants is constructed in mainstream and the academic world. With my interest in domestic violence, I found a gap in the research on understanding the experiences of women after they leave abusive relationships. I know people who have experienced abuse and the challenges they encounter accessing resources after they leave the abuser, which motivate me to conduct this research study. 


\section{CHAPTER 2: BACKGROUND}

\section{Immigration policies impacting abused women}

Canada is a country where diverse families migrate due to its multicultural policies of valuing diversity and pluralism (Merali, 2009). In Canada, individuals can apply as permanent residents on four grounds: Family Class Immigrants (overseas or in Canada), Economic Class Immigrants, Refugees and/or under Humanitarian and Compassionate (H\&C) grounds (Alaggia, Regehr, \& Rishchynski, 2009)

Family class applicants are citizens and permanent residents who sponsor their spouses or family members to Canada. Research shows that wives make up sixty percent of sponsored individuals. (Alaggia et al., 2009; Merali, 2009). Spousal application can be done 'In Canada' or outside Canada. An 'In Canada' application is when a person living without status in Canada is sponsored by a citizen or permanent resident. Spousal applications are done outside Canada

('Overseas'), and when approved the sponsored person becomes a permanent resident, allowing him/her to live, study, and work in Canada. Sponsors are required under the family class immigration policy to support the sponsored individual for three years upon their arrival in Canada (Alaggia et al., 2009). In situations where the spouses are no longer living together, the sponsor is expected to support the sponsored person so the sponsored person will not depend on social assistance. Generally, sponsored persons are not eligible to receive social assistance. However, when a sponsored person receives social assistance due to an experience of abuse, the sponsor is required to repay back to social assistance the amount the sponsored person received (Alaggia et al., 2009; Merali, 2009). Due to the repayment policy, abused women do not seek assistance because of fear for their safety and threats of deportation by the spouse. 
Immigration laws have also subjected women to abuse. For instance, women are expected to be dependent on their sponsors for three years and this sometimes leads to sponsorship debt for women. Sponsorship debt occurs when sponsors bring wives to Canada usually through arranged marriages. This arrangement makes the wife responsible for the cost of sponsorship. (Merali, 2009). In this case, the wife is expected to work and repay the husband for the money or else she is at risk of deportation. Abuse then occurs as wives are subjected to doing all the house chores, giving her work earnings to the husband, and being isolated from the community (Alaggia et al., 2009). Dependency on the spouse creates a power difference as the sponsored person may be reluctant to report abuse due to deportation fears if they are non-status immigrant or they have broken the three year spousal dependency rule.

Women who choose to leave an abusive relationship may also face challenges when seeking assistance .Resources offered in the community not accessible and they also have to deal with the language barrier.

Additionally, as identification is required whiles seeking assistance, it is a challenge for women without legal status, as they will not have the required identification and this will make them ineligible to receive assistance (Hyman et al., 2006).

In understanding the intersectionality of women seeking resources, it is important to understand how race and gender influence women's decision to take action in the relationship. Barriers that are posed by these immigration policies intensify for immigrant women as gender and class intersect with their minority status when accessing resource after an abuse (Burman, 2005). Sokoloff (2008) argues:

Since colonization is such an important part of the immigrant movement of people from one country to another, this becomes an important part of understanding the intersectional and interlocking analysis of domestic violence in immigrant communities in the U.S. This 
should ultimately lead to greater understanding of how African American women, Latina women, and more recent immigrant women, like those from South Asian countries, differ in terms of their responses to domestic violence. (p. 236)

Immigration laws have subjected men to power and left women powerless. Burman \& Chantler (2005) argue for the British “"one-year rule' which gives the husband the right, and power, to have the woman deported from the country" (p. 65). With this type of rule, individuals who have experienced some sort of violence can apply on humanitarian and compassionate grounds (Alaggia et al., 2009). However, the decisions to accept the claims on humanitarian and compassionate grounds are subjective to individual cases. The immigration officers use their discretion to determine whether the claims would be approved or not. Claims that have been denied cannot be appealed. For women who have experienced abuse, their hope of applying for permanent stay is not guaranteed. They are expected to make a non-refundable payment for which there is no guarantee their claim would be approved.

In protecting women to understand their status as a sponsored person, some positive changes were made in 2000 on the sponsorship contract in Canada (Merali, 2009). Sponsored persons were required to sign a form which explained their rights as a sponsored person. The form included information such as sponsors do not have to right remove a sponsored person from the country and in the case of abuse; women can seek safety by applying for social assistance (Merali, 2009). These changes were a step in the right direction as it enabled sponsored a person to be aware of their status in Canada. The forms are however inaccessible as they are only available in English. This poses a challenge for the sponsored person as she is required to read and sign the form. The changes made to the new form did not consider issues of language accessibility and the how a language barrier places abused women in a vulnerable position. 
Different countries and cultures have varying beliefs, norms and values. Within some countries, domestic violence is tolerated and it is not viewed as a crime, however it is not tolerated in other countries (Erez, Adelman, \& Gregory, 2009). However certain policies and laws can be abusive and perpetuate violence. 


\section{CHAPTER 3: LITERATURE REVIEW}

Issues of domestic violence are linked to broader structural forces which have resulted in the oppression of women. To understand domestic violence among immigrant women, it is important to realize the issue does not only happen to an individual or within a cultural framework. Sokoloff (2005) argues that:

We must look to understanding the intersectionality of these structural and cultural institutions as we struggle against domestic violence in all communities - and especially the most marginalized in a society that is built on the intersection of multiple models of social inequality. (p. 244)

Having examined the literature, there are four key factors that influence immigrant women's decision to stay or leave an abusive relationship: resource availability, voices of women, police and criminal justice involvement and lastly, advocacy service for abused women.

\section{Resource Availability}

The needs of individuals leaving an abusive relationship are diverse. Alaggia et al.,(2009) state that Canada is noted as one of the countries with advanced domestic violence policies and services such as crisis lines, shelters, domestic violence special teams and more. Nevertheless, immigrant and refugee families face barriers accessing these resources when compared to nonimmigrant women. Generally, the needs of women leaving an abusive relationship include legal assistance, education, transportation, housing, child care, job, and financial assistance (Bui \& Morash, 2007; Leslie, 1996; Sullivan et al., 1992; Wilcox, 2000). However, barriers based on societal structure, ethno-cultural environment, language, lack of knowledge on resources, and fear of deportation prevent immigrant and refugee women from accessing resources (Alaggia et al., 2009; Fugate, Landis, Riordan, Naureckas, \& Engel, 2005; Kulwicki et al., 2010a). 
An immigrant woman may have limited knowledge on where they can get access to information about domestic violence. Vidales (2010) argues that immigrant women may not be aware of the services that are available, as well as not being able to speak the official language of the country. Language becomes a challenge when women cannot access information or services due to language barriers. In Canada the official languages are French and English, thus language becomes inaccessible when the individual seeking assistance does not speak or understand any of the languages in the host country (Erica Briones-Vozmediano, Goicolea, Ortiz-Barreda, GilGonzález, \& Vives-Cases, 2014; Bui \& Morash, 2007; Haeseler, 2013).

A study by Simich, Beiser, Stewart, \& Mwakarimba (2005), focused on the service provider's view on the availability of social supports that are available for immigrant women. The service providers discussed that the inaccessibility of resources for immigrant women are due to inadequate funding that affects the agency's service provision. This affects immigrant women when some agencies are not able to meet their needs, such as providing translators or interpreters due to funding issues. Another service provision issue that was addressed in the research was status eligibility; the status of some women's immigration acts as a hindrance from accessing the agency's resource. In cases where service are only offered to permanent resident or citizens, nonstatus or refugee women will not be able to seek such resources. The service providers also discussed the bureaucratic processes within the agency, racism and lack of understanding of immigrants needs by the agency's staff. To support this study, Sokoloff \& Dupont (2005) argue:

The need to question the primacy of gender becomes apparent when one realizes that the violence and control by an individual batterer is not the only form of violence experienced by marginalized battered women. Instead, the lack of adequate institutional support in the form of social services and public housing as well as the intrusions and coercive controls by the state and its agencies (e.g., welfare) is another level of violence experienced by battered women, which occur in ways that are racialized as well as gendered and classed. (p. 44). 
These cultural, structural and institutional barriers also affect women's responses to the abuse by deciding whether to leave or stay in the relationship (Bhuyan \& Senturia, 2005; Briones-Vozmediano et al., 2014; Kasturirangan \& Williams, 2003). Economic difficulty is another barrier that influences an immigrant women's decision to seek assistance, especially when the woman is financially dependent on their spouse. Through migration and the sponsorship process, a woman might not have employment or the financial means to sustain her when she leaves the abusive relationship (Alaggia, Regehr, \& Rishchynski, 2009; Kulwicki, Aswad, Carmona, \& Ballout, 2010a; Vidales, 2010). Accessing safe, stable and affordable housing is paramount, especially for women leaving an abusive relationship. The lack of safe, stable and affordable housing put women at risk of compromising their safety to facing an unstable housing situation or homelessness (Ponic et al., 2011; Raj, A., Silverman, 2002). In a study by Bhuyan \& Senturia (2005), participants identified housing as an important need because they did not want to choose between the abuse and being homeless. Women are faced with choosing between having to return to their abuser due to the marginalization they experience in accessing housing needs, or staying in a shelter after they have left their abusers. Ponic et al. (2011), states that $31 \%$ of Canadians using shelters planned to return to their abusers because of issues accessing housing. The process of obtaining housing involves complex administrative and bureaucratic processes. For example, the processes involved in obtaining short-term transitional or second stage housing have a precise requirement which might not meet the needs of all women. Consequently, some of these individuals such immigrant women, women of color, women using substances, or those with male teenage children are excluded from accessing resources through agency's process and requirement (Ponic et al., 2011). An economic need such 
as the housing processes can dis-empower women to access resources, and as such influence women's decisions to stay.

In some agencies, translators are accessible for women, however women might be worried about their safety as the interpreters might be from their community (Guruge \& Humphreys, 2009). A woman's safety is put at risk when confidentiality is broken and information about her location is shared with other members in her community. Some immigrant women may also use their spouse or family member as a translator. In the case of abuse, their spouse cannot be used as translators if they want to report the abuse and other family members can only be used if they are trusted (Haeseler, 2013). Language barriers are evident in programs that are organized in reaching out to abused women such as newspapers or radio stations are not in diverse languages, this way it makes it hard for women to understand where to seek help (Bhuyan \& Senturia, 2005)

It is important to recognize the structural forms of oppression such as racism, heterosexism, economic exploitation that are embedded in society (Kasturirangan, Krishnan, \& Riger, 2004; Wachholz \& Miedema, 2000). Due to societal oppression, some women seek informal help from their support system such as family and friends. Family members that have beliefs in family unification may use shame, gossip and guilt to aid women into staying in the abusive relationship (Ansara \& Hindin, 2010; Hyman et al., 2006.). This behavior influences women to stay in the abusive relationship. Due to migration and the resulting separation from family, some immigrant families have limited support from their extended family members who are not in their current host country. As such when they experience abuse and they decide to leave the abusive relationship, they might not receive the emotional or economical support from their family members (Vidales, 2010). For other women, formal resources that support women 
after they leave an abusive situation were not common in their home countries, and as a result, they lack the knowledge of the fact that support and services are available. The challenges women experience accessing community resources impacts their decision to stay or leave the abusive relationship.

\section{Voices of Abused Women}

In understanding women's behaviour and experiences whilst seeking formal resources, it is important that they be represented in the services they receive. This is important because it helps service providers to effectively evaluate their services, and understand how they meet the needs of women. Unfortunately, the voices of women (especially minority women) have been overlooked when understanding the effectiveness of services that are provided after women leave an abusive relationship (Simmons, Farrar, Frazer, \& Thompson, 2011). Ono (2013) argues that the voices of marginalized women in domestic violence have been pushed aside. As a result, this section will focus on studies that have explored women's experiences from leaving an abusive relationship, and thus allow their voices to be heard.

Immigrant women lack a strong network of social service support when women start experiencing abuse, and this is significant when women decide whether to leave the abusive relationship (Davis, 2002). The experiences of women seeking outside resources influence their decision to leave or stay in the abusive relationship (Briones-Vozmediano, Goicolea, OrtizBarreda, Gil-González, \& Vives-Cases, 2014; Kim \& Gray, 2008; Ponic et al., 2011). Simmons et al. ( 2011) argue that after a woman experiences abuse, there are three decision-making stages that influence her decision to seek help. These stages are influenced by her interpersonal factors such as individual and relational history and socio-cultural factors such as economic, political, 
and cultural context. Within the three stages of defining the problem, deciding to seek help, and selecting a source of support, a woman decisions are influenced by her experiences.

Reina \& Lohman (2015) studied the experiences of immigrant Latina women to understand their experiences as they seek outreach services. The study found that the barriers in services have prevented these women from seeking advocacy and community resources. This is an important point because the women in the study felt that the government had a duty to help and protect them; however the discriminatory practices and attitudes of staff created unwillingness for them to seek social service. The women further explained that as they sought social assistance after leaving their abuser, the attitude of government employees was disrespectful and the women believed these attitudes were based on stereotypes workers had of them.

Simmons et al., (2011) research focused on suggestions from abused women on how to improve services. In the study, the survivors of domestic abuse discussed that services should be comfortable for the women. This included ensuring confidentiality, that women feel cared for and providing connections to other victim or survivors. With respect to comfort in service, in the Shiu-Thornton, Senturia, \& Sullivan (2005) study, the women stated they need trustworthy people whom they can confide in and help them deal with their abuse. The women indicated that they need a supportive group to help them deal with the abuse, whereas the men also needed a 'batterers program' to help them address their abusive behaviours. The women also suggested the removal of barriers such as language, transportation and criminal and legal response in services. Some women expressed they needed legal assistance to help them through the court process, supportive counselling, interpreters, and translators to help them to know the services that are available (Shiu-Thornton et al., 2005). The women stated that they are more likely to 
seek support when they believe their needs will be addressed within the organization (Simmons et al., 2011).

To further understand the diverse experiences of minority women who have accessed culturally specific agencies compared to the mainstream agencies, Gillum's 2009 study focused on the experiences of African American women who had used both culturally specific and mainstream services. Their findings were that some women experienced some issues with the mainstream agency and positive experience with the culturally specific agency. The women in the study felt the culturally diverse agency has services that addressed their diverse needs whereas the mainstream agencies had fewer resource and as such some of their complex needs were not been addressed within the agency. The women were also of the view that the culturally specific Afrocentric environment was welcoming and this helped their self-esteem and confidence. Another important factor that they addressed was the staff; the women felt they could relate to the staff as they were a representative of themselves as either being African American or a survivor of abuse themselves.

\section{Police and the Criminal Justice System (CJS)}

The police play an important role in the criminal justice system as they are the first emergency contact women encounter when they call for support in an abusive relationship. Kim \& Gray (2008) argue that women who want to leave an abusive relationship need protection. The primary role of the criminal justice system for abused women is assisting women to obtain civil protection order (Shorey, Tirone, \& Stuart, 2014). The response an individual receives from the police influences the abused woman's response to the abuse. 
Some police actions cause some women to feel the police are unhelpful in responding to their abuse. In the Vidales (2010) study, a woman described her experience; she was not fluent in English and the police did not bring bilingual assistance even though she told the officer she did not understand English. She describes how she was ignored as the officer started a hearty conversation with her husband about soccer. Vidales (2010) states that "Police attitude and behavior reflect societal perceptions of domestic violence and the status of women in U.S. society" (p. 539). The article discussed that some policemen were not only sexist, but also racist, which impacts women's decision to seek help. As such, some women are reluctant to call police because they felt they will not receive the help or assistance they want.

In addition, some women did not report the issue to the police because they wanted to preserve their relationship, and if the police got involved it might mean they will have to end the relationship (Fugate et al., 2005). Vidales (2010) argues:

Minority women are often reluctant to call the police in the first place because they are unwilling to subject their private lives to uncaring strangers who might exacerbate the situation by discriminating against them or by using excessive force against their partners. (p. 539)

Due to discrimination in the criminal justice system (CJS), when women call the police it can result in the arrest or incarceration of their partners. Studies have argued that the police and criminal justice system do not solve women's problems; it does not favor certain abused women such as minorities but rather it hurts them (Sokoloff \& Dupont, 2005b; Sokoloff, 2008). With regard to women without legal status, Shorey et al., (2014) argue they do not seek assistance from the police due to fear of being deported. The community and church are the support for these women; however, they were encouraged to stay with their male partners. 
The CJS and women's perspectives of the justice system play a role in women's attitude towards reporting of the abuse. In Canada, federal and provincial mandatory arrest policies have been implemented to increase CJS involvement due to IPV as well as to reduce the discretion of IPV and hold perpetrators accountable for their behaviours. This was a zero-tolerance policy that was established in the 1980's (Barrett, St. Pierre, \& Vaillancourt, 2011). Mandatory arrest has been criticized as it is believed to disempower immigrant women in making their own decisions when experiencing abuse. The policy also creates barriers for women, especially if they are dependent on their spouse. In instances where their spouse is removed due to an abuse, the women may face barriers such as loss of financial assistance, linguistic support, systemic racism and others (Singh, 2010). Barrett et al. (2011) states:

It is interesting that although women in some socially and or economically marginalized populations were significantly less likely to desire the arrest or punishment of their partners, visible minority women, Aboriginal women, low-income women, religious women, and women whose primary household language was not English or French were all significantly more likely to indicate that the police took their partners away. (p. 54)

Immigrant women may put themselves at risk of deportation because there is no assurance of protection from the police (Raj, A., Silverman, 2002; Singh, 2010). These barriers in the policies and immigration status has influenced and made it difficult for immigrant to seek assistance during abuse.

\section{Advocacy Services}

Domestic violence advocacy services focus on working with and on behalf of women who have experienced abused on the individual and institutional level. Organizations that provide direct services to women are either local or community based (Wood, 2014). Shorey, Tirone, \& Stuart (2014) argue that advocates are usually individuals who have experienced abuse 
and as a result they are motivated to advocate for other victims. They provide support and a link between women seeking social service and the institutional agents (Bennett, Riger, Schewe, Howard, \& Wasco, 2004).

Advocacy for abused women encompasses different social institutions such as the criminal justice system, health care system, and social services that impact women who have experienced abuse. These institutions are focused on helping women as they seek resources such as housing, child care, employment and others (Allen, 2004; Bennett et al., 2004; Shorey et al., 2014). Advocacy programs are important because when the needed supports are present within their diverse programs, women are able to access community resources and it gives them a sense of empowerment (Shorey et al., 2014). For example, women's shelters serve as a form of advocacy through their efforts to assist access to community resources within the shelters. There are different advocates within shelters that focus on the critical area of the woman's needs such as employment and legal needs (Allen, 2004).

Furthermore, community based advocacy is vital especially when women are unaware of the community resources as they can help victims or survivors access necessary resources (Allen, 2004). For example, in community collaboration, some police units work alongside victim services, in which a victim advocate responds together with the police during domestic violence cases. They accompany the police on their first response to provide support, crisis intervention, and service referral to the victim. There is also collaboration between the police and the community agency in which the police will notify the agency after they respond to domestic violence issues. This way the agency is able to assist with offering available service for the victims (Shorey et al., 2014). 
Through a coordinated approach, women receive counselling based on their needs and presenting issues. However Shorey et al., (2014) argues that the counselling women receive is different as it is based on the organization's approach to grief, substance abuse, psychoeducation, and other issues. The counsellors also try to deconstruct power; control and gender inequality whist counselling women. Counselling may be in groups, individual, or women may be referred outside to mental health professionals depending on the woman's needs (Bennett et al., 2004; Morgan \& Coombes, 2013; Shorey et al., 2014).

Children are important when women are leaving an abusive relationship and as such when women leave their abuser, they tend to leave with their children. When women are placed in shelters, advocates work effectively to provide the children with their necessary needs such as food, clothing, and counselling when needed. Counselling is significant for children to help them cope especially when they have been exposed to the abuse (Bennett et al., 2004; Shorey et al., 2014).

Advocacy is also significant at the institutional level as it aims at changing the broader policies and practices that oppress abused women, as they give voice for abused women (Merchant \& Whiting, 2015; Shorey et al., 2014). However, the approaches that guide advocate practice when working with survivors were either focused on survivors or collaborated with the survivor. These approaches vary and are important because they enable survivors to take control over the services. 


\section{CHAPTER 4: THEORETICAL FRAMEWORK}

Immigrant women face multiple oppressions based on their race, religion, class, immigration status and others. These oppressions have resulted in placing immigrant women in disadvantageous social positions which have influenced their experiences and response to DV. This research applies theories of critical race feminism (CRF) and intersectionality to analyze the interlocking oppression of women that have influenced their social position, their experiences and response to domestic violence. This section will focus on understanding the emergence of these theories and how it is applicable to this study.

CRF can be defined "as a body of writing that attempts to integrate the way race and gender function together in structuring social inequality" (Dua, 1999, p. 9 cited in Sajnani, 2012). The theory argues that mainstream feminist theory does not acknowledge the realities of sexism, classism, and of Black women and other women of color. CRF emerged from critical race and critical legal theory. As a result, $\mathrm{CRF}$ focuses on how legal and social policies assist or oppress racialized women (Few, 2007). This theoretical framework is centered on the multiple forms of oppression and discrimination women experience due to their intersection identities of race, class, and gender (Evans-winters \& Esposito, 2010). CRF aims at combating gender and racial oppressions by recognising the multiple identities that result in their oppressions.

Critical race feminism drew its ideas from critical race theory (CRT) and critical legal studies (which included feminism). Black and other minority scholars developed CRT because they believe the legal discourses in as Critical Legal Theory were not applicable to people of color (Aylward, 1999). Critical Legal Theory acknowledges from feminist theory, the gender oppression and inequality within a patriarchal society. Critical legal studies focused on the critiquing of traditional and realist jurisprudence by white academic men (Evans-Winters \& 
Esposito, 2010). In drawing ideas from Feminist Legal Theory, CRF rejects some mainstream feminist ideas such as the essentialism of all women and not paying attention to the subordination of women of color. Essentialism was also prevalent in CRT, and as a result, CRF rejected the essentialization of all minorities by CRT. In this way, the theory was antiessentializing as they believed identity was not additive but rather multiplicative. The theory does not essentialize women of color and as a result, it recognizes the diversity and difference among women of color and their multiple and intersecting identities (Wing, 1997). It also focuses on empowering women to improve their status by engaging women of color in discussions of the issues they face.

CRF places women of color at the center, and explains the intersecting identities of women on the basis of gender, race, class, sexuality, ability and others (Clarke, 2012; Wing, 1997). It focuses on these identities as it examines the multiple intersecting discrimination women of color experience through these identities. In understanding the intersecting identities, intersectionality framework will be used with CRF as they support the similar ideologies.

With respect to intersectionality and domestic violence, the theory was introduced by Kimberle Crenshaw. Crenshaw was a Black feminist legal scholar, who was trying to understand the discrimination in the labor force through an analysis of race and gender (Josephson, 2002). Crenshaw examined how black women and other women of color faced oppression due to their combined identity of race, sex, and class. Through Crenshaw's work on intersectionality, the theoretical framework was used as a tool to examine the lives of women who had experienced domestic abuse through the lens of racism and classism (Crenshaw, 1991). Crenshaw argues that there are systems of power that are created within our identities of race, gender, class, sexual orientation and others (Crenshaw, 1991). Within the social context, structural inequalities exist in 
the identities which results in an intersecting hierarchy leading to oppressions, unearned privilege and domination (Erez et al., 2009). The theory helps to understand how oppression and privilege work through social interactions. Intersectionality identifies the different identities or systems that influence an individual's experience as their identities intersect (Crenshaw, 1991). Bograd (1999) argues:

Intersectional ties color to the meaning and nature of domestic violence, how it is experienced by the self and responded to by others, how personal and social consequences are represented, and how and whether escape and safety can be obtained. (p.276)

This shows how inequalities within systems of power affect women's intersecting identities, which influence their decision of leaving or staying in an abusive relationship.

In relating intersectionality and $\mathrm{CRF}$ to domestic violence, Crenshaw used intersectionality to understand the discourses on domestic violence from mainstream and victim services on domestic violence (Crenshaw, 1991). The discourses and services are focused on white women while ignoring the types of domestic violence on women of color. Intersectionality helps to understand the meaning and types of domestic violence, the experiences of people and how the issue is responded to, personal blame versus social blame and the experiences in regards to escaping and safety. Bograd (1999) states, "In this framework, domestic violence is not a monolithic phenomenon" (p. 276). The identities of immigrant women are affected by wider social and historical oppressions such as racism and sexism, and these oppressions can impact women's decisions on how to deal with domestic violence (Kulwicki, Aswad, Carmona, \& Ballout, 2010). As an individual decides to act on their abusive relationship, they might have to prioritize their racial/ethnic identity over gender in dealing with racism and sexism. (Meyer, 2012). Barriers that are posed by policies intensify for immigrant women, as gender and class 
intersect with their minority status when accessing resources after an abuse (Burman \& Chantler, 2005).

Intersectionality helps to understand the experiences of individuals by analyzing the interlocking hierarchies. A group-based experience of oppression does not disappear in intersectionality, but rather it helps to understand how domination varies across individuals within the same group (Josephson, 2002). It is helpful in understanding women who have experienced domestic violence and the experiences they faced whilst accessing community resources. Sokoloff \& Dupont (2005) argues that in order to understand the complexities of a battered woman's experience, it is important to realize that the women's oppressions are usually multiplied based on of the intersections of their race, gender, and immigrant systems of oppression and discrimination. Kasturirangan et al. (2004) states that "sexism and racism are not mutually exclusive; rather, the intersectionality of their multiple identities complicates minority women's experiences of violence" (p. 320).

Women's lives are impacted by the interlocking factors such as race, gender and class (Pitt, 2008). Josephson (2002) argues that through structural intersectionality, issues of accessing shelter must be addressed as immigrant women or women of color face additional challenges. An immigrant woman might deal with their domestic violence differently, especially when their immigration status is dependent on their abuser. An immigrant woman's decision not to take action will differ based on the individual, as domestic violence is not a homogenous experience. However, their intersecting identities of immigration status, sexuality, religious and cultural beliefs influence their decision and experiences. Pitt (2008) argues "women may be reluctant to seek 'official help' because of their fear of the institutional racism that are embedded in policies" (p. 64). One aspect of an individual's identity can contribute to understanding the other 
identities. An example would be how immigration status, gender, and sexuality contribute to the understanding of race and vice versa. Each identity becomes important in recognizing how the other identities are manifested and experienced by women (Pitt, 2008).

Critical race feminism is important in this research because research on women's violence have focused on using feminist theories to explore how gender inequalities have resulted in the oppression of women. Thus research has ignored the interlocking identities of women, and has prioritized gender as the center of its analysis. Racial and ethnic minorities have not been the focus, and as such intersectionality fills this gap. Intersectionality has focused on examining the other forms of oppression and inequalities to understand how they intersect (Sokoloff \& Dupont, 2005). Feminist scholars have undermined other identities as more attention is focused on gender inequalities and ignoring other identities of race, class, immigration status and others (Kasturirangan et al., 2004). 


\section{CHAPTER 5: METHODOLOGY}

This study will use phenomenology to deeply understand the experiences of service providers who have firsthand experience working with immigrant women. It will focus on examining immigrant women's experience utilizing formal resources after they leave an abusive relationship. Phenomenology will be used in this research to achieve the following objectives: to examine resources and challenges women leaving an abusive relationship face; service provider's views on women's experiences accessing resources; and to identify recommendations on how to meet the needs of immigrant women when they seek assistance.

Phenomenology focuses on the essential existence of a phenomenon by understanding the meanings that are attributed to an experience (Moustakas, 1994; Starks \& Trinidad, 2007). Phenomenological research centers on the lived experiences of a phenomenon (Starks \& Trinidad, 2007). This methodology will be used in this research because it focuses on getting a deep understanding of the lived experiences when describing a particular phenomenon (Engnes, Lidén, \& Lundgren, 2012; Starks \& Trinidad, 2007). It also aims at exploring the common essence in different experiences, which helps to understand the meanings that get created through those experiences. Phenomenological research aims to understand people's experiences in the world, and as such phenomenologist questions the lived experiences of participant to find common themes. These themes help to gain a deeper understanding of the meanings that are ascribed to their experiences (Pascal, Johnson, Dore, \& Trainor, 2011). In this study, the narratives of service providers will be used to gain an understanding of the experience of women accessing services after leaving an abusive relationship. In trying to understand the experiences, Engnes et al., (2012) argue phenomenology focuses "on the description of a phenomenon, which 
is an object as experienced by a subject" (p. 2). In the study, the experiences of the service provider in relation to women's service utilization are the object in the study and the impact it has on the women are the subject. Service providers are used in this study as they have a deep understanding of the services that are available. By using service providers instead of service users, this study does not risk further intrusion in the lives of the women.

\section{Data Collection}

The research seeks to explore the views of service providers by examining the services that are available in meeting the needs of immigrant women leaving an abusive relationship. As such, this study used narrative principles to do an in-depth interview with three service providers for an hour. The interviews were audio recorded on my phone and transcribed by myself with permission from the participant.

Narrative-based interviewing assists in acquiring an intensive understanding of the meanings that service providers assign to their experiences (Chase, 2003). The interview question focused on the stories of the participant; however probes were used to inquire deeper into their stories. Through the interviewing process, I engaged with the participants to understand their experiences working with abused women. This was done by using probing questions such as "Tell me about....", “Then what happened?", "Can you give me an example?" to get richer stories of their experiences.

The interview was an interactive and a joint production between the narrator and the interviewer (Wolgemuth, 2013). Through an inter-subjective interviewing process, the questions aimed at the experiences of the service providers rather than generalizing to other workers. For example, I asked participants to tell me about a training program they have taken that focused on 
meeting the needs of immigrant women, instead of focusing on what the agency has offered to all workers.

The interviews were transcribed verbatim by the researcher. I analyzed the stories line by line to understand the themes that arise. Fraser (2004) argues that even "studies with relatively few participants are liable to produce many more stories than can be possibly analyzed in any one article, report or thesis" (p. 186). In this case the transcription was important as I analyze the stories line by line by reading it multiple times to assign code labels. This detailed analysis helped to get an in-depth understanding of the information and themes that exist in the transcribed data (Fraser, 2004). Codes were thematically analysed to find similar and different patterns. The codes that were found from the service providers experiences were then grouped into themes.

In making this research transformative, I made the atmosphere conducive to building up trust between myself and the participant. The participants choose their preferred location for the study. The locations were places where the participant's confidentiality could be maintained. This was important because the participants were be free to ask questions, make clarifications, and also allow me to express my understanding of what the participant is articulating. Due to confidentiality, pseudonyms will be assigned to the three participants. 


\section{CHAPTER 6: FINDINGS}

This study focused on the experiences of three service providers who work with abused immigrant women. The findings from the interview process show that the participant's experiences whilst working with abused women were similar within their diverse agencies, but also different in some way. The analysis focuses on the intersecting identities such as immigration status, race, language skills, class, and gender that impact women as they seek community resources. The findings reflect the following three areas: services within their agency such as a shelter; the broader system which included other community resources women utilize; and the broader structural issues such as budgets and finances that affect service provision. The pseudonyms (P. A), (P. B) and (P. C) were assigned to the participants to maintain confidentiality.

\section{Services}

Services are the immediate response for women when they escape an abusive relationship. These services focus on meeting the needs of women by providing supports such as housing support, language assistance, and child care as women leave their abusive relationships. This section of the analysis will focus on the challenges that immigrant women experience when accessing services such as language barriers, subtle oppression, the worker-client relationships, the agencies' approach to working with immigrant women, and the trainings workers receive.

\section{Language Barriers}

To understand the barriers immigrant women experience, I asked the service providers about some of the challenges they experience as they worked with immigrant women. An important issue that emerged was the language barrier. Service providers stated that language was a 
challenge especially when they were working with abused women who spoke little to no English.

A service provider expressed that:

Another challenge is when the women do not speak English, it is hard to communicate with them so we need to find an interpreter and sometimes it takes time which can make it difficult for the women and workers when they have to wait for an interpreter to express their (women) needs and concerns. (P. C)

As Canada is a bilingual country, English was not the only struggle for women who did not speak it. Some women also experience some struggles even if they spoke French because services were not provided in French.

The client we have now, we had these language barriers because she spoke French and none of us speaks French. But she could speak English but minimal...we hired a translator for us to be able to assist her with housing service and legal aid. (P. A)

This quote highlight the barriers women experience when they are aware that Canada is a bilingual country, as women might assume resources will be accessible in French. This affirms the inaccessibility of community resources in diverse languages for immigrant women. However this is challenging because sometimes the workers only speak English, which becomes a challenge for women who only speak French, and challenges the bilingual nature of the country. Another participant further explained that:

Sometimes it is hard to understand each other when English is not their first language. And sometimes they have accents like we try our best to understand each other, and it takes creation and more time for immigrant women. (P. B)

Even when women speak English, it is a problem for the workers because they are not able to understand them due to their accents. Women cannot change their accents. The quotes do not only highlight the inaccessibility of resource when language is a barrier. 
The location of an individual can also impact their language accessibility. Women might be expected to access other community resources such as interpreters or ESL. This is problematic for immigrant women who do not speak English, as they have to be put on waitlist to access resources while shelter workers find a translator. This cause more delays for them compared to individuals who speak English.

\section{Subtle Oppression}

The service providers expressed how immigrant women's actions were perceived differently by different workers. And these perceptions can sometimes affect women's experiences in shelters. One of the issues discussed was the lack of acknowledging differences among people. As stated by a service provider:

In my work place I am the only immigrant, everybody is white. No other racialized employee. So the thing is we had this African client before and the way she speaks was loud and boisterous. But some of my colleagues would take that and use that against her. For them it's disrespectful and she will get warning for that. Because sometime some people will not be able to understand that she speaks that way or that tone, because she is used to being like that. (P. A)

This quote reflects the oppression immigrant women experience due to their identities.

The subtle racism women experience within these shelters based on the minor issues such as the way the women spoke. Service providers might be aware of why the women are "othered", however the women might not be aware of the impact of her difference. She might be experiencing subtle oppression within the agency that adds to the abuse she is already dealing with. As immigrant women are considered as the "other" due to their differences in mainstream society or cultural expectation, there is the reinforcement of the dominant and superior culture which places a negative undertone about immigrant women as inferiors.

Another service provider supports this by emphasizing that: 
Sometimes, the cultural difference is hard. Like the way women treat their children and things. So we had a woman who wanted to sleep with her baby, however this was a safety concern for us but as a worker I was worried to address it with her because I wasn't sure if it was a cultural practice and I didn't want it to seem like am not respecting her culture ... My supervisor addressed it with her but she told us she was comfortable sleeping with her child. So we had to call CAS because of safety reason and it was not allowed at our agency. This was really hard for her because she felt like she was going to lose her children. I remember her telling us she doesn't trust us and that's why she didn't want to come to shelters. It was a really difficult situation but we tried to manage it, she found a place later on and moved from the shelter. (P. C)

This creates the binary of the "norm" (western) versus the "other" (non-western), what is culturally accepted vs. what is not accepted.

Also, the quote shows the power service providers have over women who are seeking services within their organization. Women experience this power relation when worker call other organizations such as the child welfare organization to deter a practice. Women experience constant surveillance within the shelter as they are monitored to ensure they are doing “appropriate" thing. Through this surveillance, women face the struggle of having to deal with both the abuse and involvement of other agency such as children's Aid society.

Immigrant women experience additional subtle oppressions within social service agencies. For women who have left an abusive relationship, food might seem like a minor concern and the expectation is that women should rather focus on their safety. However, food can play a role for the abused women, especially when they have just newly migrated to the country and are not used to the meals that are provided at the shelter. P.A. explained that in their shelter, women will give a list of the groceries they need to the workers and they go out to buy for the women. The shelter is also in a small city and they do not have diverse groceries stores available. As such women face the barrier of accessing their cultural meals when they are in the shelter. One of the service providers explained: 
We have limited budget...we cannot provide everything for these women. So let's say, groceries. We do not provide Native groceries for them like the traditional [food]. We don't really have it, unless we can get it with the groceries they have or we can order it. We have this distributor we contact them and if they have it we can provide it but if they don't we can't. (P.A)

We are trying to but it's hard for us because it is a long drive going into the Asian store. And it's like what I said, we don't have budget as much as we want to. Let's say, we had a client who wanted Indian food but we can just provide her with some that are with the distributor place. And if someone [worker] is willing to drive somewhere far then we can do it. But if not ... (P. A)

This quote reflects that women's needs are at the discretion of worker. I further explored this point with the participant, specifically regarding the women's feelings when they do not receive their cultural meals. The service provider explained:

They [the women] get frustrated for sure but they have to accept the fact that they are living in a shelter and we don't have enough budgets for that. Our mandate doesn't support all the traditional food they need but what we can just provide is the main service that we can give them such as protective housing, counselling, and legal assistance. Those are the things we can provide first things that we can provide but for food not really. But we can provide free food, free groceries but it is not cultural based. (P. A)

Despite workers attempts to assist the women in meeting their needs, they are limited in the assistance they can give women due to funding and budget. As much as housing, counselling and all the other resources women require are also important. A seemingly minor thing such as food can be equally important. These "little" factors can impact women's decisions to use or not use mainstream services and as such go back to their abuser.

In general when women are not able to deal with the struggles within the agencies, some women return to the community as they are not able to depend on social services. A service provider discussed:

Some women leave and return to their abuser, others go to family member, other shelters and some of them we do not know where they go to. And I mean they go for different 
reasons such as not been able to deal with the rules in the shelter, CAS involvement due to allegations and others. These women end up even feeling more isolated than they came here with. As much as we try to help these women some of them end up at worst places because the systems fail them. (P. C)

For immigrant women, due to migration, they have limited social supports and as such when they go back to the community, they face a cycle where they become less visible in their communities. This is significant when there are barriers due to the women's intersecting identities. For immigrant women who do not speak English and are faced with abuse, their isolation is severe, especially when they do not have other people they can depend on after the system has failed them.

Another thing that is challenging to immigrant women is, generally we might not see them in the community. So for example they might be in the home providing home or taking care of the children or house chores because every culture is different. So sometimes they might just be in the home lonely or might not be outside meeting other people so they very isolated. (P. B)

This quote reinforces the isolation women face as a result of the lack of support from both family and the community. They tend to stay within their home focusing on meeting their family's need. For service providers, reaching out to these women is challenging because they are not visible in the community.

\section{The Worker-Client relationship.}

In the interviews, I explored with the participants the diversity across workers and how that plays a role when abused women came into the shelter. One worker explained in the position for women:

... What I am thinking is, it easy I guess because you might go to a person who understands what you are going through, because she [worker] is also an immigrant and so she [worker] knows the difficulties and at the same time she is worker. Whereas if you go to a worker who is not an immigrant they might not be able to understand or a possibility they might not understand what you are going through aside from being an abused woman. (P. A) 
Another worker discussed working with abused women when they have not had the same experiences as the women, and the challenges of understanding those experiences when the worker has not experienced it themselves:

My biggest barrier is trying to understand the women's experiences when I haven't lived their experiences. I remember in school I learned to put myself in my client shoes. However it is challenging to do that because I have not lived their experience. So with me, I just try to understand the women experiences and empathize with her on it. (P.C)

\section{Approaches to working with the women}

Service providers explained that whilst working with immigrant women, they are usually open-minded and respectful to the women as they try to understand their struggles. However, they also focus on empowering women to be self-reliant, and encourage them to do things on their own with the support of staff. Service providers explained that they try to help women take the lead in making decisions that would help themselves, while the worker provides support.

So because we try to encourage empowerment, sometime we provide information for clients to do it themselves ... Sometimes if they feel more comfortable being present or make a call on behalf of them, it may depend on the situation, it makes sense for us .... To work together with them to call the person to find the specific information for them.... so we try not to do things for them, we try not do things for them. for example if it is the citizenship application, we encourage them to go online and fill as much as possible and then we go over what they have said for them to change or if we need to do another one. But some people feel more comfortable as we tell them what to do but they bring the document and we do it together. (P. B)

The service provider also explained how empowerment similarly played out within their shelter when women move into the shelter and they are looking for housing. "A person can stay as long as they need to or have to but as much as possible we empower them; help them find their own apartment space as fast as we can" (P. B). Another participant stated: 
However whilst working with the women we focus on empowering them so that when they leave they would be able to do certain things on their own. As workers we focus on their strength whenever we work with them, respectful of their cultural background (P.C)

\section{Training}

To understand the knowledge that service providers working with immigrant women have and their struggles dealing with the abuse and their immigration status, I asked participants to tell me about some training courses they have received, the focus on the training, and how effective the training were when working with this diverse population.

I attended some cultural "suppose" training, but I didn't feel them helpful ...but basically this is what it said you will get from the training but after we did not feel any information about cultural or ethnic or working together with diverse population ... the training was by a different agency about working with diverse population and what ended up happening was they were promoting their services at their agency rather than talking about what would be some skills that will enable worker work with diverse population. (P.B)

Another service provider explained the training she received and how helpful they were.

I had this Refugee training but not immigrant specific.....the training helped to understand the way they think, their mental health, the flaws, capacity, their strength, and the best way you can help them. (P. A)

This participant went further to explain that to address issues of micro-aggression within

cultural difference, a training course that would be helpful is cultural competence training.

... I think cultural competence training; I know for a fact they say cultural competence is a new form of racism, but for me as a person it depends on how you are going to work around it, you can be a racist by informing cultural sensitivity. If you are going to use that as discriminatory process or remark on the people, but if you are going to use that to help or support other people especially immigrant then I don't think that should be a problem ... You won't be able to learn everything in training, you need to do emersion, you need to know how they live, everything, but I guess cultural competency opens the minds of the workers to at least ask whenever they encounter these clients. Like the sensitivity is there whereas if you don't know or have the cultural competency program, you don't know how to deal with these people, you won't even ask, you will just follow the rules. (P. A) 
The idea of cultural competency was challenged by another service provider as they expressed that:

... I am not sure a cultural competency would be helpful as every culture has their own norms and values and even with the different culture there are just additional norms and values that are specific to individual norms and values. To work with a group of people teaching that, this is the norm, you might be generalizing the population. Things to address, we do not want to generalize or acknowledge they exist. So maybe the training should be named something else. Because cultural competence to me is like we are going to talk about one culture and how to work with them and it seems like we are generalizing and not like acting as if we know what we know is appropriate for the culture instead of asking them what is best for them. (P.B)

The participants expressed the importance for service providers to receive training that will help them understand the impact of domestic violence on immigrant women. Nevertheless, some participants stated they had received some training such as cultural competencies however they criticized it for not acknowledging the difference in people. As such, the participant discussed the importance of directly seeking information from women rather than depending on training they have received.

\section{Community Systems}

Barriers accessing community resources affected women who wanted to depart from shelters and reintegrate safely in the community. This section will focus on the wait time when accessing community resources and the lack of coordinated services with community agency when working with abused women.

The service providers discussed the extensive waitlist which can be discouraging for women, especially immigrant women who do not have family members that they can depend on whilst they wait. 
Sometimes they need help applying for community housing. For housing if you are in an abusive relationship, then they prioritize you but there is still a wait list getting into a home because you have no home because of the abuse situation...Generally, I think its 35 years...but it depends on how many different places you select. If you select only certain place and designated living space then it is very low that you will be able to get housing. But if you select the entire region then there is a possibility you will get housing. If you reject two times by the third time if you don't take it then they put you back on the bottom of the wait list. (P. B)

This response was reinforced by another service provider:

Like housing, we [workers] provide the application but they [the women] need to go to the housing organization ... So let's say the client is unemployed, she is not able to support herself right, she was just depending on the ex-partner...if the women are going to apply for housing it will be difficult for them because the government will not be able to give them housing unless you are under OW or ODSP. And there is a very long wait list and with the housing it can take up to 7 years. So in that case, they have to apply for welfare, or OW or ODSP so they can get a regular monthly income and then look for market rent. (P. A)

The aforementioned quotes reflect the struggles that women face when they try to access stable housing after they leave an abusive relationship. The struggle comes with its own impact and consequences. As one of the participants explained below:

Most women that come into our shelter are in need of permanent housing. The process and the wait time that women experience are discouraging especially when women are dealing with all the emotional impact of abuse. I remember one woman we worked with could not just wait for the process. She needed a place to stay because she had 4 children and she said she was not comfortable in the shelter. We helped her apply for government housing but it was taking forever so we advised she considered taking market price housing until she got government housing. But...she didn't have money for market price housing and $\mathrm{OW}$ was also not enough to take care of the children and pay for rent as well. She ended up leaving the shelter and returning to her abuser. (P.C)

This quote shows the strength of abused women and the weakness in the system. As women have gained strength to leave their abuser, the struggles they experience can push them back to their abuser and this was evident with the aforementioned story. 
The participants discussed the lack of coordinated services and the impact it had on the women. Service providers explained the limited resources in their agency which caused some of the women to seek other services outside their agency, such as financial assistance and housing. The struggles that these women experience can impact them in ways that can be re-traumatizing for some women, as they try to navigate within the system to ensure their needs are met after they have left their abuser.

Within our agency, we provide services such as helping the women apply for housing, social assistance. However with these places, the women would have to go through the housing process which can be challenging and sometimes re-traumatizing for the women as they need to proof to the housing people she has experienced abuse. The idea of telling and retelling all the different agencies their story or abuse is challenging for the women. It is really hard for them because even after telling their stories they would have to wait before they get the OW or housing. This wait time can take forever especially for the housing and so some women would want to get regular housing which cost a lot more money than the government housing. (P. C)

The process of women re-telling their stories to other service providers is almost as if the women are re-living their experiences. Service providers discussed this problem as the system being ineffective. However, as service providers there is little they can do to prevent this, as women need to access the external resources in order to be qualified for other resources that are not offered in their agency.

Another participant went further to explain the struggles women face when these women have utilized social assistance and the cycle it creates. The participant explained that the system is structured in a way that creates a dependency. When women work, there is less support from social assistance and when the women do not work they receive more support. It is challenging for women as they become dependent on the system, as the system does not support them into independence. 
They (social assistance) might shrink it because they are balancing how much money you have based on your income. So women have told me that it makes no sense for them to work because social assistance gives them enough for day care but when they start working um social assistance does not give enough money for them to pay for day care or have enough money for other things like food, housing, clothes. They have told me this doesn't make sense for them to work, it better to depend on the social assistance cheque only. And later on when their children are older they get the issue where they don't have experience, how will they get any type of job. then they end up with low paying job, how are they going to do low paying jobs not a lot of skill is need even you. It's kind of the system that creates this problem and they involve the women not being able to work to secure a better paying job. (P. B)

Another service provider added that another challenge for these women is when they do not have any form of identification, especially when they are refugees or non-status immigrants. The shelter would advocate for legal support to assist these women because without the identification, the women cannot apply for any government assistance program. This causes them to wait and stay longer in the shelter.

You have to wait and sometimes the women do not have ID. So in that case they need legal support. So we provide legal support so they need this paper works to fill out so that they can get an ID and all that stuff. (P.A)

There needs to be a coordinated holistic approach to services which will work with shelters or other agencies that are working with women in a way that the women would not have to re-tell and re-live their experiences. In the process, the information that is collected when women arrive at their initial intake would be accessible to other collaterals that are working with the abused women. Within some communities, there are coordinated service interventions with the criminal justice system. This facilitates assisting women in the legal realms as the flow of information is appropriately shared. This information can be shared with service providers that are assisting women such as housing services, doctors, counsellors to ensure women are not have to live their trauma over again. 


\section{Structural Barriers}

Shelter or other agencies play an important role when meeting the needs of abused women. However, these shelters or agencies are challenged due to budgets and funding constraints. The limitation in funding causes constraints on the programs and services that are offered in the shelter. This creates challenges for workers because as much as they would want to provide certain services, they are limited in what they can offer. One of the participants stated that "Everything depends on the budget, because we cannot provide services if we don't have a budget" (P.A) and she further explained that and as such they have to find other ways to raise extra money. "Say as an example the government provides funding, we also have a fundraising project that we sell second hand items that helps with our budget" (P.A). In understanding the advocacy services that are provided to women, a service provider explained how the limitedness in budget affects their assistance to the women. The service provider explained that when women go to court, it would be appropriate for workers to go with them; however due to limited funding this kind of advocacy service is not available to all agencies. The service provider explained that agencies within bigger cities receive more funding than those within smaller cities. As such, depending on the location of the agency, when they receive more funding they are able to provide more advocacy services. The service provider explained how appropriate it would be to support women through their court process but unfortunately funding does not support such assistance and some women are left to deal with the legal system by themselves.

It might depend on the individual situation, I had a co-worker that attended court with a woman who was in an abusive situation, Generally attending court is not in our duty of what is suggested to worker because that is the piece that is not really funded by the organization. This might be available in bigger cities. In our community it is through a different organization that helps women through the court procedures. However depending on the individual woman's situation it might make sense for the worker to take 
the woman to court um but like driving her to and from court would not be a piece. Attending court may make sense. Show support to the consultation in court. (P. B)

The service provider explained that this sort of service can be offered through another organization. However for women who have built trust and rapport with worker, finding a different agency that will assist them through the court process can be challenging; as the women would have to build new trust and this can take time as well as delay the women's process involving the court process.

\section{Discussion}

Service providers expressed their thoughts on the experiences of abused women when they utilise their agency. The findings showed the dissatisfaction in their services for abused women, which impact women as they leave an abusive relationship. The issues that were addressed by the service providers were due to barriers in services, the lack of coordinated service and funding and budgeting related issues within the agency. The challenges immigrant women experiences within these systems create problems where the women's needs are not met appropriately. The analysis in the study examines how the diverse intersecting identities of race, class, immigration status impact their resource utilization.

The study also showed the difference in how immigrant women's attitudes were perceived by other workers. The difference affected how service providers approached and perceived the actions of these women. The power that service providers have over these women can negatively impact how they approach these abused women. As demonstrated in the literature, when service providers work from an ethnocentric view, their views on immigrant women's abuse will be subjected to what they know and as such create additional discrimination 
for immigrant women (Wing, 1997). The findings showed that the difference in how women presented themselves influenced how they were treated in the shelter. The participant expressed that when workers viewed women's actions as a 'threat' to themselves, women are at risk of facing consequences to their action. The participants acknowledge that these actions of workers are subtle however it shows the power that services provider have over abused women within these agency. Service provider's attitude towards women and their experience can affect women's decision to stay or leave and return to their abuser. It is important that staffs are trained to understand domestic violence and how it intersects with immigration and cultural difference. This training should emphasize service providers being respectful of client difference when working with immigrant population.

Issues of providing women with their appropriate needs, such as food that are at the discretion of service providers or funding limitations, shows the subtle racism women can experience within the agencies. A participant discussed this situation which sometimes pushes women to choose between their needs and the abuse they are experiencing. Latta \& Goodman (2005) supports that as much as food might seem as a trivial issue with abuse women, some women starved themselves in the shelter due to unfamiliarity with the food provided to them. The study argues that the availability of appropriate food creates a welcoming atmosphere for women who are seeking assistance in these agencies.

Participants explained the lack of resource information for women who have not experienced abused as also being an issue. This is problematic because these women might not have the words to describe their experience or trust the workers when they experience abuse. Consequently, when this type of information is not given to them they might not talk about their 
abuse. Women who are seeking other resources such as language assistance might not be aware they provide counselling or other services to women who are experiencing abuse. As such some women might also not inquire whether services are provided to women who are experiencing abuse.

The findings also suggest having a diverse staff within social service organizations; these diverse workers can be immigrant women, women from diverse cultural background, or women who have experienced abused. One service provider expressed that having diverse workers might make the client more comfortable, as the worker might better understand what they are going through because they can relate to some extent. It would be important for agencies' staff to reflect on the services they provide and strive to better meet the needs of the women which they serve.

As identifies in the literature, the findings supports that there is a need for a collaborative approach to service when working with abused immigrant women (Shorey, Tirone, \& Stuart, 2014). These collaborative services will focus on working effectively to reduce the risk associated when abused women leave the abusive relationship. The study found the inadequacy of service or the system resulted in women returning to their abuser. A coordinated service where housing support worker, mental health professional and law enforcement are present creates a safe place for women, as these would decrease some of the challenges women face when accessing these resources separately. Another issue that was addressed in the study was language barriers when women access services. A collaborative approach with agencies that provide language services would be appropriate when language is a barrier. The language agency will provide language support when there is a language barrier in services. These agencies that 
provide language support should also receive training on issues of domestic violence and immigrant to better assist this population.

The relevance of intersectionality in relation to these findings, suggests that there are multiple oppressions that women experience due to their intersecting identities. The service provider expressed that immigrant women face barriers such as continuously proving their immigration status when they access community resource and issues in accessing high earning jobs due to lack of Canadian employment history. When women are also working low paying job, they are unable to get certain assistance such as child care and as such they are put in a position where they depend on social assistance. These forms of interlocking oppressions make it difficult for women who have left an abusive relationship. Women seeking community resource such as social assistance or housing are expected to show their identification and proof their status in Canada. This is a challenge for non-status women because they might not have this identification and as such they would require legal support. This process is time consuming and becomes a challenge for women who need financial assistance or permanent housing.

The findings also addressed the challenges service providers experience due to limited funding. This limit in funding for social services affects the kind of services that are provided to immigrant. Similar findings were reported in Simich, Beiser, Stewart, \& Mwakarimba (2005) study of immigrant and refugee women in Canada; “... responsibilities for immigrant settlement, health and social services are underfunded and uneasily divided between national, provincial and local jurisdictions, confounding accountability for service gaps related to immigrant health and giving the Canadian cities where most immigrants settle little influence over the integration process" (p. 266). This is supported by one of the participant who expressed that they are not 
able to provide certain service because they are in a small city and funding is not provided for that. However funding is accessible to other people in bigger cities. The structural barriers of funding affect immigrant women when they leave an abusive relation because their needs are not met when funding constrains the agency.

The themes in this research show that the issues of immigrant women who have left an abusive relationship need to be properly addressed from different perspectives. This will help understand the issue well and provide appropriate services for these women. The approach will focus on the service, community and structural level to meet the interlocking needs and identities of the women. 


\section{CHAPTER 7: IMPLICATION AND CONCLUSION}

Services that are provided to women when they are leaving abusive relationships are crucial as it impacts women's experiences. The findings from the study showed some barriers when women access these services. The service providers offered some factors that will help immigrant women who have left an abusive relationship. An increase in awareness of services at the onset would be important for women as they migrate to the country. The issue raised by the participants suggested that the information of domestic violence and places that offer support for abused women should be accessible to all family whiles they are entering Canada. This would enable the immigrant women to know the supports that are available.

In addition, the service providers suggested that there is need for an intensive training for individuals who are working with abused women. The importance of training that will focus on understanding the struggles and trauma some people have experienced such as wars, forced marriages and how those factors implicate women's abuse and their help seeking behaviour. The education for service providers will enable workers to effectively assist women who might seek service after they leave their abuser. Workers will have an understanding of the women's lack of social support, and the trauma of retelling their stories when they seek assistance. This knowledge will impact the delivery of services for immigrant women. This form of training will also assist workers to understand their own biases and views when they are working with abused women to prevent racism. An understanding of the workers' views and the women's history and migration process, will enable the service providers to be able to assist them better, since they will be able to engage with the clients and understand them more effectively. 
As women seek other community resource such as housing, legal assistance, service providers should also advocate for the women. Service providers should be educated on the ways that they can advocate for women in order for their needs to be met in the community. This would be helpful because the services providers will act as a support for the women. Supportive services should be explored within services in which the women are supported and their needs are met and empowering to the women. These supportive services would advocate for women at different levels to ensure women's needs are met and the women will have a sense of independence when they exist the social service agency.

It is important that immigrant women's needs are addressed when they access community resource. Latta \& Goodman (2005) argue that when agencies do not meet the needs of women, these experiences not only impact the women, but members of her community as well. As a result when women have a negative experiences of service, there is a likelihood people from her community will have similar perspective.

\section{Limitations}

There are a number of limitations of this study. This research is an exploratory research which explored service provider's perspective on women's service utilization after they leave an abusive relation. The research focused mainly on service because that is what service providers were able to account for. They could not specifically address the women's feeling in regards to the service they receive. This has created a limitation in the study, however the service provider have worked with abused women in different capacity and the examples the participants used in 
the research brought forth some of the women's experiences. Finally, the small sample size limits the generalizing of these findings to workers beyond those interviewed in this study.

Future research on this issue should use immigrant women to understand their own views and perspective on their experiences after they leave an abusive relationship.

\section{Conclusion}

There are various factors that impact women when they experience abuse and these factors affect their decision to stay or leave an abusive relationship. These factors include immigration status, employment, language barrier and children. This exploratory study focused on understanding women's experiences when utilizing social services after they have experienced abuse. Service providers were interviewed to understand the services that are provided to women within the various agencies and their experiences working with immigrant women.

The findings demonstrated women's intersecting identities were a key factor in the barriers women experience whiles they utilize social services. Social services that serve abused women are responsible for providing effective service which will support women when they leave an abusive relationship. However, service providers expressed that they face barriers such language and cultural differences whiles assisting immigrant women within their agencies. As such, these factors limit the effectiveness of the service women receive as they seek social support. It is important to recognise that as much as service providers hope they can assist women effectively, certain systemic barriers such as funding limit their ability to assist these women. Additionally structural issues that impact immigrant women are embedded in policies and evident based on women's intersecting identities such as their immigration status and class. 
This study has demonstrated the complicated and interconnected barriers that women experience after they leave an abusive relationship in search of a safe place; the complexities for women accessing service within other community organization and the barriers they face such as waitlist, retelling of their stories, and proving their status in the country. Consequently, a coordinated community approach between social services will be beneficial when assisting abused immigrant women. These services will provide effective and partnered service between different service providers and the abused women.

While these findings are very important and support the studies in the literature review, given the small sample in this study, further research is needed to fully document the barriers that immigrant women face when accessing services after they leave an abusive relationship. 
Appendix A

Recruitment Email

\section{Study Title: \\ SO I LEFT, NOW WHAT? \\ SOCIAL SERVICE WORKERS PERSPECTIVE ON IMMIGRANT WOMEN'S SERVICE UTILIZATION AFTER LEAVING AN ABUSIVE RELATIONSHIP}

Hello,

My name is Shirley Asiamah. I am currently a student at the Ryerson University and I am conducting a research as part of my study in Masters of Social Work Program. The research aims at exploring service provider's perspective on immigrant women's experience in accessing and utilizing community resource after leaving an abusive relationship. I am seeking a small sample of individuals who have firsthand experience working with abused immigrant women as participants for the study.

The focus of this study is to explore what immigrant women's go through when accessing and utilizing community resource after leaving an abusive relationship. Many campaigns are focused on encouraging women to leave an abusive relationship however there is a gap in the resources that are available after women leave. The study aims at addressing this issue from the service providers perspective as they have knowledge about available resources and the gap in service required to meet immigrant women's needs.

The study requires participant to engage in a 1 to 1.5 hours audio record interviewing, which will be done either in a private room in Ryerson University campus or a location of your choice. This study is voluntary; participant can choose to skip questions or redraw from the study at any time. Confidentiality would be assured throughout the research process.

The Ryerson Research Ethic Board has reviewed and approved this study. I look forward to hearing from you. For more information please contact me at sasiamah@ ryerson.ca.

Thank you.

Yours sincerely, Shirley Asiamah 
Appendix B

Consent Form

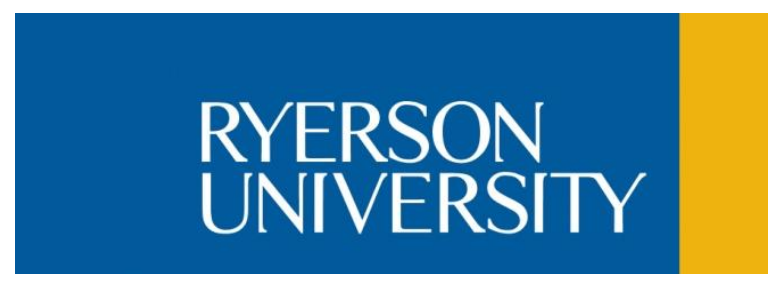

SCHOOL OF SOCIAL WORK

FACULTY OF COMMUNITY SERVICES

\section{Ryerson University \\ Consent Agreement}

You are being invited to participate in a research study. Please read this consent form so that you understand what your participation will involve. Before you consent to participate, please ask any questions to be sure you understand what your participation will involve.

\section{SO I LEFT, NOW WHAT? \\ SOCIAL SERVICE WORKERS PERSPECTIVE ON IMMIGRANT WOMEN'S SERVICE UTILIZATION AFTER LEAVING AN ABUSIVE RELATIONSHIP}

INVESTIGATORS: This research study is being conducted by

Shirley Asiamah-MSW Student

Susan Silver - Supervisor from the School Of Social Work at Ryerson University.

\section{PURPOSE OF THE STUDY:}

The study aims at exploring service provider's perspective on immigrant women's experience in accessing and utilizing community resource after leaving an abusive relationship. This will be done through a qualitative in-depth interviewing of 4 social service workers who have firsthand experience working with immigrant women in exploring these experiences. It seeks to examine services that are available in meeting the needs of women leaving an abusive relationship, the workers views on women experiences whiles seeking assistance and recommendation for the women's needs. The study hopes to contribute to this area of research.

WHAT YOU WILL BE ASKED TO DO: If you volunteer to participate in this study, you will be asked to do the following things:

- You will be required to participate in a face to face interview with the researcher.

- This research will take place at the Ryerson University or a preferred location of your choice.

- The research will be one session for about 1-1.5 hours. 
- You will be asked about your experiences working with immigrant women in relation to resources and services that the women need after they leave an abusive relationship.

\section{POTENTIAL BENEFITS:}

I cannot guarantee, however, that you will receive any benefits from participating in this study. However, the research will contribute to filling the gap in understanding the experiences of the immigrant women service utilization after they leave an abusive relationship.

Recommendations would be made in this research which would contribute to creating knowledge within this area in social service.

\section{WHAT ARE THE POTENTIAL RISKS TO YOU AS A PARTICIPANT:}

There will be low risk in this research. Some of the low risk includes: You have to take time off your normal duties to participate in this study and the time frame of the study will be challenging. The length of time is challenging because the study will take about 1-1.5 hours of your time. There is also a risk if, other people such as your colleagues, your employer, etc. finds out about your participation in the study. You might also be uncomfortable talking about things that might have happened at your work place. There could be a risk to you and clients if you reveal any information about clients that might lead to mandatory reporting to children's aid by the researcher.

\section{CONFIDENTIALITY:}

Your identity will be kept confidential throughout the research. I will use pseudonyms (Fake names) to identify participants. However, there will be a breach in confidentiality if there is any disclosure of abuse or harm through the interview process. This is because I have a duty as a social worker to report issues of abuse that are disclosed. The student researcher (myself) and supervisor will be the only ones with access to the data. Data will be deleted from audio device after a year. Laptop and USB used for the study will be password protected. Transcribed data will be stored on password protected laptop.

\section{VOLUNTARY PARTICIPATION AND WITHDRAWAL:}

Participating in this study is completely voluntary. You can choose whether to be in this study or not at any time. If any question makes you uncomfortable, you can skip that question or end the interview. If you choose to stop participating, you may also choose not to have your data included in the study. Your choice of whether or not to participate will not influence your future relations with Ryerson University or the investigator (myself) involved in the research.

QUESTIONS ABOUT THE STUDY: If you have any questions about the research now, please ask. If you have questions later about the research, you may contact.

Primary Investigator

Shirley Asiamah

sasiamah@ryerson.ca

Supervisor 
Susan Silver-(416)-979-5000 ext 6216

ssilver@ryerson.ca

This study has been reviewed by the Ryerson University Research Ethics Board. If you have questions regarding your rights as a participant in this study please contact:

Research Ethics Board

c/o Office of the Vice President, Research and Innovation

Ryerson University

350 Victoria Street

Toronto, ON M5B 2K3

416-979-5042

rebchair@ryerson.ca 


\section{Appendix C}

\section{Interview Guide}

Participating in this study is voluntary. If any question makes you uncomfortable, you can skip it at any time or end the interview. If you choose to stop participating, you may also choose to not have your data included in the study. Confidentiality will be kept throughout the interview and research process. Do not provide any identifying information of client such as names or addresses.

1. Tell me about your client population?

2. How often do you provide services to an immigrant woman who has left an abusive relationship?

3. Tell me about the needs of the immigrant women when they come to you? Can you provide an example?

4. Tell me about some challenges that have come with them accessing resources that are in your agency. Tell me about services provided by other agencies.

5. Tell me about some challenges you face or have faced whiles working with them? Can you please provide some examples?

6. Can you tell me about some barriers you have encountered whiles working with the women.

7. Tell me about any specialized trainings that you have received to help you meet the needs of immigrant women? Were they helpful?

8. Can you tell me about the agency's approach to working with abused women

9. What are your experiences in accessing other resources in the community that are not offered at you agency

10. Do you feel services you provide meet the needs of women? Any recommendations on meeting these need? 
11. Is there anything more you would like to share or address? 


\section{REFERENCE}

Alaggia, R., Regehr, C., \& Rishchynski, G. (2009). Intimate partner violence and immigration laws in Canada: How far have we come? International Journal of Law and Psychiatry, 32(6), 335-341. doi:10.1016/j.ijlp.2009.09.001

Allen, N. E. (2004). Battered Women's Multitude of Needs: Evidence Supporting the Need for Comprehensive Advocacy. Violence Against Women, 10(9), 1015-1035. doi:10.1177/1077801204267658

Aylward, C. (1999). Intersectionality: Crossing the Theoretical and Praxis Divide. Transforming Women's Future: Equality Rights in the New Century: A National Forum on Equality Rights (Conference Paper), 1(1), 4-7. Retrieved from http://www.criticalraceinquiry.com/pdf_files/articles/VOL001.1/Aylward_444447.pdf

Barrett, B. J., St. Pierre, M., \& Vaillancourt, N. (2011). Police Response to Intimate Partner Violence in Canada: Do Victim Characteristics Matter? Women \& Criminal Justice, 21(March 2015), 38-62. doi:10.1080/08974454.2011.536057

Bennett, L., Riger, S., Schewe, P., Howard, A., \& Wasco, S. (2004). Effectiveness of hotline, advocacy, counseling, and shelter services for victims of domestic violence: a statewide evaluation. Journal of Interpersonal Violence, 19(7), 815-829. doi: $10.1177 / 0886260504265687$

Bhuyan, R., \& Senturia, K. (2005). Understanding domestic violence resource utilization and survivor solutions among immigrant and refugee women: introduction to the special issue. Journal of Interpersonal Violence, 20(8), 895-901. doi:10.1177/0886260505277676

Bograd, M. (1999). Strengthening domestic violence theories: intersections of race, class, sexual orientation, and gender. Journal of Marital and Family Therapy, 25(3), 275-289. doi:10.1111/j.1752-0606.1999.tb00248.x

Briones-Vozmediano, E., Goicolea, I., Ortiz-Barreda, G. M., Gil-Gonzalez, D., \& Vives-Cases, C. (2013). Professionals' Perceptions of Support Resources for Battered Immigrant Women: Chronicle of an Anticipated Failure. Journal of Interpersonal Violence, 29, 1006-1027. doi: $10.1177 / 0886260513506059$

Briones-Vozmediano, E., Goicolea, I., Ortiz-Barreda, G. M., Gil-González, D., \& Vives-Cases, C. (2014). Professionals' perceptions of support resources for battered immigrant women: chronicle of an anticipated failure. Journal of Interpersonal Violence, 29(6), 1006-27. doi:10.1177/0886260513506059 
Briones-Vozmediano, E., La Parra, D., \& Vives-Cases, C. (2014). Barriers and facilitators to effective coverage of Intimate Partner Violence services for immigrant women in Spain. Health Expectations, n/a-n/a. doi:10.1111/hex.12283

Bui, H. N., \& Morash, M. (2007). Social Capital, Human Capital, and Reaching Out for Help with Domestic Violence: A Case Study of Women in a Vietnamese-American Community. Criminal Justice Studies, 20(4), 375-390. doi:10.1080/14786010701758146

Burman, E., \& Chantler, K. (2005). Domestic violence and minoritisation: legal and policy barriers facing minoritized women leaving violent relationships. International Journal of Law and Psychiatry, 28(1), 59-74. doi:10.1016/j.ijlp.2004.12.004

Campbell, A. (2009). Intersections of violence : the role of immigration status in women' $\mathrm{s}$ experiences of and responses to domestic violence in Canada.

Chase, S. E. (2003). learning to listen : narrative principles in a qualitative research methods course. In R. Josselson, A. Lieblich; D. P. McAdams (Eds.) Up close and personal: The teaching and learning of narrative research. Washington, DC: American Psychological Association, 79-99

Clarke, J. (2012). Beyond Child Protection: Afro-Caribbean Service Users of Child Welfare. Journal of Progressive Human Services, 23(3), 223-257. doi:10.1080/10428232.2012.719119

Crenshaw, K. (1991). Mapping the margins: Intersectionality, identity politics, and violence against women of color. Stanford Law Review, 43(6), 1241-1299. doi:10.2307/1229039

Davis, R. E. (2002). Leave-taking experiences in the lives of abused women. Clinical Nursing Research, 11(3), 285-305. doi:10.1177/10573802011003005

Engnes, K., Lidén, E., \& Lundgren, I. (2012). Experiences of being exposed to intimate partner violence during pregnancy. International Journal of Qualitative Studies on Health and Well-Being, 7, 1-11. doi:10.3402/qhw.v7i0.11199

Erez, E., Adelman, M., \& Gregory, C. (2009). Intersections of Immigration and Domestic Violence: Voices of Battered Immigrant Women. Feminist Criminology, 4(1), 32-56. doi:10.1177/1557085108325413

Evans-winters, V. E., \& Esposito, J. (2010). Other People's Daughters :, 11-25.

Few, a. L. (2007). Integrating Black Consciousness and Critical Race Feminism Into Family Studies Research. Journal of Family Issues, 28(4), 452-473. doi:10.1177/0192513X06297330 
Fraser, H. (2004). Doing Narrative Research: Analysing Personal Stories Line by Line. Qualitative Social Work, 3(2), 179-201. doi:10.1177/1473325004043383

Fugate, M., Landis, L., Riordan, K., Naureckas, S., \& Engel, B. (2005). Barriers to domestic violence help seeking: implications for intervention. Violence against Women, 11(3), 290310. doi:10.1177/1077801204271959

Gillum, T. L. (2009). Improving services to African American survivors of IPV: from the voices of recipients of culturally specific services. Violence against Women, 15(1), 57-80. doi:10.1177/1077801208328375

Golding J.M. (1999). Intimate Partner Violence as a Risk Factor for Mental Disorders: A MetaAnalysis. Journal of Family Violence, 14(2), 34. doi:10.1023/A:1022079418229

Guruge, S., \& Humphreys, J. (2009). Les obstacles à 1 ' accès aux services de soutien et à leur utilisation chez les immigrantes victimes de mauvais traitements Barriers Affecting Access to and Use of Formal Social Supports, 41, 64-84.

Haeseler, L. A. (2013). Practitioner perspectives of the economic coping experiences of women of domestic violence abuse. Journal of Evidence-Based Social Work, 10(1), 1-9. doi:10.1080/15433714.2012.751004

Hyman, I., Forte, T., Mont, J. Du, Romans, S., \& Cohen, M. M. (2006). Help-seeking rates for intimate partner violence (IPV) among Canadian immigrant women. Health Care for Women International, 27(March 2015), 682-694. doi:10.1080/07399330600817618

Hyman, I., Mason, R., Helene, W., Manuel, L., \& Kanagaratnam, P. (2006). Perceptions of and Responses to Woman Abuse Among Tamil Women in Toronto, 25, 145-150.

Josephson, J. (2002). The Intersectionality of Domestic Violence and Welfare in the Lives of Poor Women, Journal of Poverty, 6:1, 1-20, DOI: 10.1300/J134v06n01_01

Kasturirangan, A., Krishnan, S., \& Riger, S. (2004). The impact of culture and minority status on women's experience of domestic violence. Trauma, Violence \& Abuse, 5(4), 318-332. doi: $10.1177 / 1524838004269487$

Kasturirangan, A., \& Williams, E. N. (2003). Counseling Latina Battered Women: A Qualitative Study of the Latina Perspective, 31(July).

Kim, J., \& Gray, K. a. (2008). Leave or stay? Battered women's decision after intimate partner violence. Journal of Interpersonal Violence, 23(10), 1465-82. doi:10.1177/0886260508314307

Kulwicki, A., Aswad, B., Carmona, T., \& Ballout, S. (2010a). Barriers in the Utilization of Domestic Violence Services Among Arab Immigrant Women: Perceptions of Professionals, 
Service Providers \& Community Leaders. Journal of Family Violence, 25, 727-735. doi:10.1007/s10896-010-9330-8

Kulwicki, A., Aswad, B., Carmona, T., \& Ballout, S. (2010b). Barriers in the Utilization of Domestic Violence Services Among Arab Immigrant Women: Perceptions of Professionals, Service Providers \& Community Leaders. Journal of Family Violence, 25(8), 727-735. doi:10.1007/s10896-010-9330-8

Latta, R. E., \& Goodman, L. a. (2005). Considering the interplay of cultural context and service provision in intimate partner violence: the case of Haitian immigrant women. Violence against Women, 11(11), 1441-1464. doi:10.1177/1077801205280273

Leslie, M. (1996). The Efficacy of Follow-Up Programs for Abused Women, 6(4), 425-441.

Louis, K. S., \& Barton, A. C. (2002). FORUM : QUALITATIVE SOCIAL RESEARCH Tales from the Science Education Crypt : A Critical Reflection of Positionality, Subjectivity, and Reflexivity in Research, 3(3).

Merali, N. (2009). Experiences of South Asian brides entering Canada after recent changes to family sponsorship policies. Violence against Women, 15, 321-339. doi: $10.1177 / 1077801208330435$

Merchant, L. V., \& Whiting, J. B. (2015). Challenges and Retention of Domestic Violence Shelter Advocates: a Grounded Theory. Journal of Family Violence, 30(4), 467-478. doi:10.1007/s10896-015-9685-y

Meyer, S. (2012). Why women stay: A theoretical examination of rational choice and moral reasoning in the context of intimate partner violence. Australian \& New Zealand Journal of Criminology, 45(2), 179-193. doi:10.1177/0004865812443677

Morgan, M., \& Coombes, L. (2013). Empowerment and advocacy for domestic violence victims. Social and Personality Psychology Compass, 7(8), 526-536. doi:10.1111/spc3.12049

Moustakas, C. (1994). Phenomenological research methods Thousand Oaks, CA: Sage

Ono, E. (2013). Violence Against Racially Minoritized Women: Implications for Social Work. Affilia, 28(4), 458-467. doi:10.1177/0886109913505044

Pascal, J., Johnson, N., Dore, C., \& Trainor, R. (2011). The Lived Experience of Doing Phenomenology: Perspectives from Beginning Health Science Postgraduate Researchers. Qualitative Social Work, 10(2), 172-189. doi:10.1177/1473325009360830

Ponic, P., Varcoe, C., Davies, L., Ford-Gilboe, M., Wuest, J., \& Hammerton, J. (2011). Leaving != Moving: Housing Patterns of Women Who Have Left an Abusive Partner. Violence Against Women, 17, 1576-1600. doi:10.1177/1077801211436163 
Raj, A., Silverman, J. (2002). Violence Against Immigrant Women. Violence Agianst Women, 8(3), 367-398. doi:10.1177/10778010222183107

Reina, A. S., \& Lohman, B. J. (2015). Barriers Preventing Latina Immigrants from Seeking Advocacy Services for Domestic Violence Victims: A Qualitative Analysis. Journal of Family Violence, 30(4), 479-488. doi:10.1007/s10896-015-9696-8

Rhodes, N. R., \& Mckenzie, E. B. (1998). WHY DO BATTERED WOMEN STAY ?: THREE DECADES OF RESEARCH, 3(4), 391-406.

Sajnani, N. (2012). Response/ability: Imagining a critical race feminist paradigm for the creative arts therapies. The Arts in Psychotherapy, 39(3), 186-191. doi:10.1016/j.aip.2011.12.009

Section 3: Intimate partner violence. (2013). Retrieved from http://www.statcan.gc.ca/pub/85002-x/2013001/article/11805/11805-3-eng.htm

Shiu-Thornton, S., Senturia, K., \& Sullivan, M. (2005). "Like a bird in a cage": Vietnamese women survivors talk about domestic violence. Journal of Interpersonal Violence, 20(8), 959-976. doi:10.1177/0886260505277677

Shorey, R. C., Tirone, V., \& Stuart, G. L. (2014). Coordinated community response components for victims of intimate partner violence: A review of the literature. Aggression and Violent Behavior, 19(4), 363-371. doi:10.1016/j.avb.2014.06.001

Simich, L., Beiser, M., Stewart, M., \& Mwakarimba, E. (2005). Providing Social Support for Immigrants and Refugees in Canada: Challenges and Directions. Journal of Immigrant and Minority Health, 7(4), 259-268. doi:10.1007/s10903-005-5123-1

Simmons, C. a., Farrar, M., Frazer, K., \& Thompson, M. J. (2011). From the Voices of Women: Facilitating Survivor Access to IPV Services. Violence Against Women, 17(10), 1226-1243. doi: $10.1177 / 1077801211424476$

Sokoloff, N. J. (2005). Domestic Violence at the Crossroads : Violence Against Poor Women and Women of Color. City, 32(3), 1-10.

Sokoloff, N. J. (2008). Expanding the intersectional paradigm to better understand domestic violence in immigrant communities. Critical Criminology, 16, 229-255. doi:10.1007/s10612-008-9059-3

Sokoloff, N. J., \& Dupont, I. (2005a). Domestic violence at the intersections of race, class, and gender: challenges and contributions to understanding violence against marginalized women in diverse communities. Violence against Women, 11(1), 38-64. doi: $10.1177 / 1077801204271476$ 
Sokoloff, N. J., \& Dupont, I. (2005b). Domestic violence at the intersections of race, class, and gender: challenges and contributions to understanding violence against marginalized women in diverse communities. Violence against Women, 11, 38-64.

doi: $10.1177 / 1077801204271476$

Soyini Madison, D. (2004) Critical Ethnography: Theory and method. Thousand Oaks, CA:

Sage Available at: http://www.sagepub.com/upmdata/4957_Madison_I_Proof_Chapter_1.pdf

Starks, H., \& Trinidad, S. B. (2007). Choose your method: a comparison of phenomenology, discourse analysis, and grounded theory. Qualitative Health Research, 17, 1372-1380. doi:10.1177/1049732307307031

Sullivan, C. M., Basta, J., Tan, C., \& Davidson, W. S. (1992). After the crisis: a needs assessment of women leaving a domestic violence shelter. Violence and Victims, 7(3), 26775. Retrieved from http://www.ncbi.nlm.nih.gov/pubmed/1294240

Thobani, S. (2000). Closing the Nation's Doors to Immigrant Women : The Restructuring of Canadian Immigration Policy. Atlantis, 24, 16-26.

Vidales, G. T. (2010). Arrested justice: The multifaceted plight of immigrant latinas who faced domestic violence. Journal of Family Violence, 25, 533-544. doi:10.1007/s10896-0109309-5

Wachholz, S., \& Miedema, B. (2000). Risk, fear, harm: Immigrant women's perceptions of the policing solution" to woman abuse. Crime, Law and Social Change, 34, 301-317. Retrieved from

http://search.proquest.com/docview/216163453?accountid=14026lnhttp://library.stanford.ed u/sfx?url_ver=Z39.88-

2004\&rft_val_fmt=info:ofi/fmt:kev:mtx:journal\&genre=article\&sid=ProQ:ProQ:abiglobal \&atitle $=$ Risk, + fear, + harm: + Immigrant + women's + perceptions + of + the +

WHO | Violence against women. (n.d.). Retrieved from http://www.who.int/mediacentre/factsheets/fs239/en/

Wilcox, P. (2000). Lone Motherhood: the Impact on Living Standards of Leaving a Violent Relationship. Social Policy and Administration, 34(2), 176-190. doi:10.1111/14679515.00184

Wing, a. K. (1997). Critical race feminism and the international human rights of women in Bosnia, Palestine, and South Africa: Issues for LatCrit Theory. The University of Miami Inter-American Law Review, 28(2), 337-360. Retrieved from http://www.jstor.org/stable/40176422 
Wolgemuth, J. R. (2013). Analyzing for critical resistance in narrative research. Qualitative Research, 14(5), 586-602. doi:10.1177/1468794113501685

Wood, L. (2014). Hoping, Empowering, Strengthening: Theories Used in Intimate Partner Violence Advocacy. Affilia, 1-16. doi:10.1177/0886109914563157 